\title{
THE ANALYSIS OF COMPOSITE BEAMS WITH PARTIAL INTERACTION USING THE GENERAL TECHNIQUE METHOD
}

\author{
Nguyen Van Chung \\ Postgraduate Student, Civil Engineering, University of Technology, VNU-HCMC \\ Bui Cong Thanh \\ Department of Structural Mechanics, Faculty of Civil Engineering
}

\begin{abstract}
This paper presents a modeling technique that derives from the work of Newmark to describe the behavior of steel-concrete composite beams with elastic shear connection. The model is used to derive expressions for beam curvature, rotation and deflection under monotonic load from which the stiffness matrix is derived and finite element analysis performed on a set of illustrative examples. Model results are compared to those obtained using other method
\end{abstract}

\section{INTRODUCTION}

Steel and concrete composite structural elements have been used in construction since the early 1920s. Mechanical connections lock together steel and concrete to cause the entity to behave as a single element. Composite beam deflections stress distribution and modes of failure are governed by the strength and reliability of the shear connection between the joined materials. To design effective composite sections, engineers must possess not only a clear understanding of the mechanical properties of steel and concrete but also the nature of the bond between them [2]. A topic of modern research into composite beam behavior addresses partial shear interaction between joined materials.

Newmark [1] derived a differential equation to describe general composite elements fabricated from dissimilar materials. Ranzi [6] used a direct stiffness formulation based on an element possessing 8 DOF to describe vertical displacement, rotation and slip. Faella [4] derived an element stiffness matrix and fixed-end nodal forces as solutions of the Newmark equation.

This paper models the partial interaction between materials in a composite steelconcrete beam fabricated with elastic shear connections placed at discrete intervals along the length of a beam. The model permits the ready calculation of elemental curvature, rotation and deflection under monotonic loads from which the elemental stiffness element can be readily obtained.

The paper compares results obtained from the model with those computed using alternative forms of FEM analyses and other methods. 


\section{MODEL FORMULATION}

\subsection{General}

Fig. 1 shows a composite beam in cross section and the assumed steel-concrete strain distribution as that found in [1]. The problem assumes:

1. The cross section is rigid and does not distort

2. The curvature is the same in both steel and concrete

3. The shear connection exhibits linear-elastic behavior as shown in Fig. 2

4. Concrete and steel exhibit linearly elastic stress/strain behavior

Denote properties section element as:

- $A_{c}, A_{r}, A_{s}$ : area of the concrete, of the reinforcement and of the steel.

- $A_{1}, A_{2}, A$ : area of the element 1,2 and of the section

- $A_{1}=A_{c}+A_{r} ; A_{2}=A_{s} ; A=A_{1}+A_{2}$

$-S_{c}, S_{r}, S_{s}$ : first moment of area of the concrete, the reinforcement and steel joist, about the abilitary reference axis.

- $I_{C}, I_{r}, I_{s}$ : second moment of area of the concrete, reinforcement and steel joist, about the arbitrary reference axis.

- $E_{c}, E_{r}, E_{s}$ : elastic moduls of concrete, reinforcement and structural steel

- $A E_{1}=A_{c} E_{c}+A_{r} E_{r} ; \quad A E_{2}=A_{s} E_{s} ; \quad A E=A E_{1}+A E_{2} ; \quad S E_{1}=S_{c} E_{c}+S_{r} E_{r}$

$-S E_{2}=S_{s} E_{s} ; S E=S E_{1}+S E_{2} ; I E_{1}=I_{c} E_{c}+I_{r} E_{r} ; I E_{2}=I_{s} E_{s} ; I E=I E_{1}+I E_{2}$

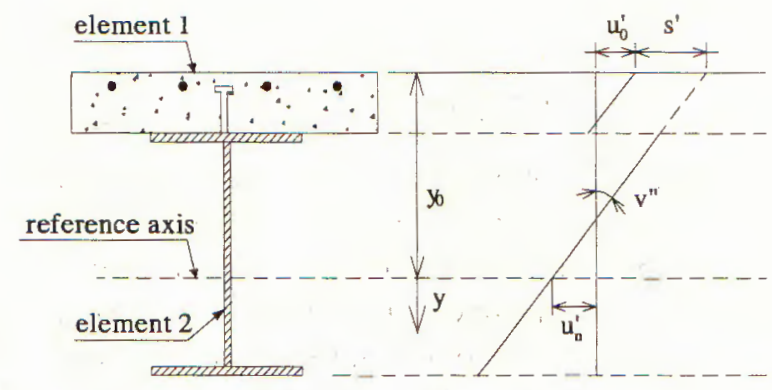

Fig. 1. Cross-section and strain diagram

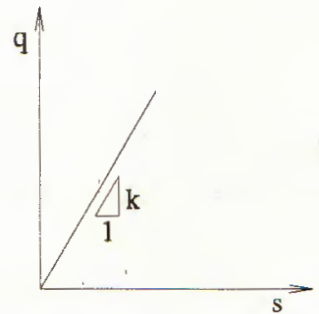

Fig. 2. Connector response

In Fig. 1 the reference $y$-axis is located a positive distance $y^{0}$ below the top of the cross-section. Axial displacements are referred to the reference axis, which without loss of generality can coincide with the top of the steel joist. $u_{0}^{\prime}$ is the top fiber strain, $u_{n}^{\prime}$ is the strain at the reference axis, $v^{\prime \prime}$ is the curvature, and $s^{\prime}$ is the slip strain that characterizes the partial nature of the interaction

Material properties can be expressed generically as:

$$
\begin{aligned}
\sigma_{c} & =E_{c} \varepsilon_{c}=E_{c}\left[u_{0}^{\prime}+\left(y+y_{0}\right) v^{\prime \prime}\right], \\
\sigma_{r} & =E_{r} \varepsilon_{r}=E_{r}\left[u_{0}^{\prime}+\left(y+y_{0}\right) v^{\prime \prime}\right], \\
\sigma_{s} & =E_{s} \varepsilon_{s}=E_{s}\left[u_{0}^{\prime}+\left(y+y_{0}\right) v^{\prime \prime}+s^{\prime}\right] .
\end{aligned}
$$


Fig. 2 illustrates the relationship between interface shear flow $q$ per unit length and slip at the interface. From [1], [2] write:

$$
\begin{aligned}
& q=k . s, \\
& k=n_{c} \frac{K}{i_{c}},
\end{aligned}
$$

where: $k$ - the shear connection stiffness (force per length ${ }^{2}$ ), $K$ - the strength of the shear connection (in Pust - test), $n_{c}$ - number of the shear connectors present at the crosssection, $i_{c}$ - shear connector longitudinal spacing.

\subsection{The model} [6].

Figs. 3, 4 illustrate an elemental beam and the upper material free body diagram. [5],
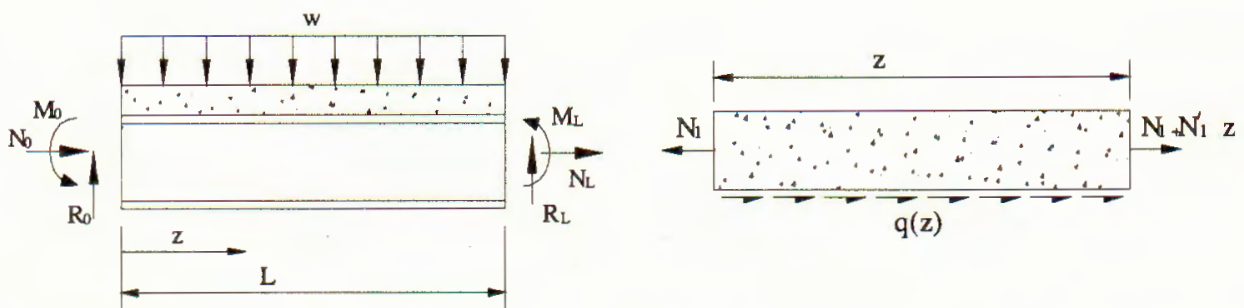

Fig. 3. General single span beam

Fig. 4. Free body diagram of the top element

\subsubsection{Horizontal equilibrium}

Consider the composite beam illustrated in Fig. 3 and Fig. 4.

$$
N=\sum_{i=1}^{2} \int_{A i} \sigma_{i} d A_{i}=N_{1}+N_{2} ; \quad M=\int_{A} \sigma y d A,
$$

where $N_{1}, N_{2}$ are the axial forces in the element 1,2 and $M$ is the bending moment

From Eq. (1) and (3), we have:

$$
\begin{aligned}
& N_{1}=\int_{A 1} \sigma d A=A E_{1} u_{0}^{\prime}+S E_{1} v^{\prime \prime}+y_{0} A E_{1} v^{\prime \prime}, \\
& N_{2}=\int_{A 2} \sigma d A=A E_{2} u_{0}^{\prime}+S E_{2} v^{\prime \prime}+y_{0} A E_{2} v^{\prime \prime}+A E_{2} s^{\prime}, \\
& N=N_{1}+N_{2}=A E u_{0}^{\prime}+S E v^{\prime \prime}+y_{0} A E v^{\prime \prime}+A E_{2} s^{\prime}, \\
& M=\int_{A} y \sigma d A=S E u_{0}^{\prime}+I E v^{\prime \prime}+y_{0} S E v^{\prime \prime}+S E_{2} s^{\prime} .
\end{aligned}
$$

Solve (5) and (6) for $u_{0}^{\prime}, v^{\prime \prime}$ :

$$
\begin{gathered}
u_{0}^{\prime}=a_{1} M+a_{2} N+a_{3} s^{\prime}, \\
v^{\prime \prime}=b_{1} M+b_{2} N+b_{3} s^{\prime} .
\end{gathered}
$$


The expressions for the rotation and deflection are obtained by integrating the curvature, the strain along the length of the beam length denoted $z$. Hence:

$$
\begin{gathered}
v^{\prime}=b_{1} \int M d z+b_{2} \int N d z+b_{3} \int s^{\prime} d z+D_{1}, \\
v=\int v^{\prime} d z+D_{2}=b_{1} \iint M d z d z+b_{2} \iint N d z d z+b_{3} \iint s^{\prime} d z d z+D_{1} z+D_{2} .
\end{gathered}
$$

Interface lip may be derived from the strain diagram as:

$$
s=u_{n}-u_{0}-y_{0} v^{\prime} .
$$

From Eq. (11), $u_{n}$ as:

$$
u_{n}^{\prime}=u_{0}^{\prime}+y_{0} v^{\prime \prime}+s^{\prime}
$$

From (7), (8) and (12):

$$
\begin{gathered}
u_{n}^{\prime}=l_{1} M+l_{2} N+l_{3} s^{\prime} \\
u_{n}=l_{1} \int M d z+l_{2} \int N d z+l_{3} \int s^{\prime} d z+D_{3}
\end{gathered}
$$

in which:

$$
\begin{gathered}
a_{1}=-\frac{S E+y_{0} A E}{A E I E-S E^{2}}, a_{2}=\frac{y_{0} S E+A E}{A E I E-S E^{2}}, \\
a_{3}=\frac{S E S E_{2}+y_{0}\left(S E_{2} A E_{1}-S E_{1} A E_{2}\right)-A E_{2} I E}{A E I E-S E^{2}} \\
b_{1}=\frac{A E}{A E I E-S E^{2}}, \quad b_{2}=-\frac{S E}{A E I E-S E^{2}}, \quad b_{3}=\frac{S E_{1} A E_{2}-S E_{2} A E_{1}}{A E I E-S E^{2}} \\
l_{1}=a_{1}+y_{0} b_{1}, \quad l_{2}=a_{2}+y_{0} b_{2}, \quad l_{3}=a_{3}+y_{0} b_{3}+1 .
\end{gathered}
$$

\subsubsection{Shear connection}

From Fig. 4 and using (4), (7) and (8), we obtain the internal axial force $N_{1}$ as [5]:

$$
\begin{gathered}
N_{1}=q_{1} M+q_{2} N+q_{3} s^{\prime}, \\
q_{1}=\frac{S E_{1} A E_{2}-S E_{2} A E_{1}}{A E I E-S E^{2}}, \\
q_{2}=\frac{A E_{1} I E-S E_{1} S E}{A E I E-S E^{2}}, \\
q_{3}=\frac{S E_{1}^{2} A E_{2}+S E_{2}^{2} A E_{1}-I E A E_{1} A E_{2}}{A E I E-S E^{2}} .
\end{gathered}
$$

Consider the horizontal equilibrium of the free body diagram,

$$
\left(N_{1}+\frac{d N_{1}}{d z} \delta z+q \delta z\right)-N_{1}=0
$$

From (2), (15) and (16),

$$
\alpha \frac{d^{2} s}{d z^{2}}-k s=\alpha_{1} \frac{d M}{d z}+\alpha_{2} \frac{d N}{d z}
$$




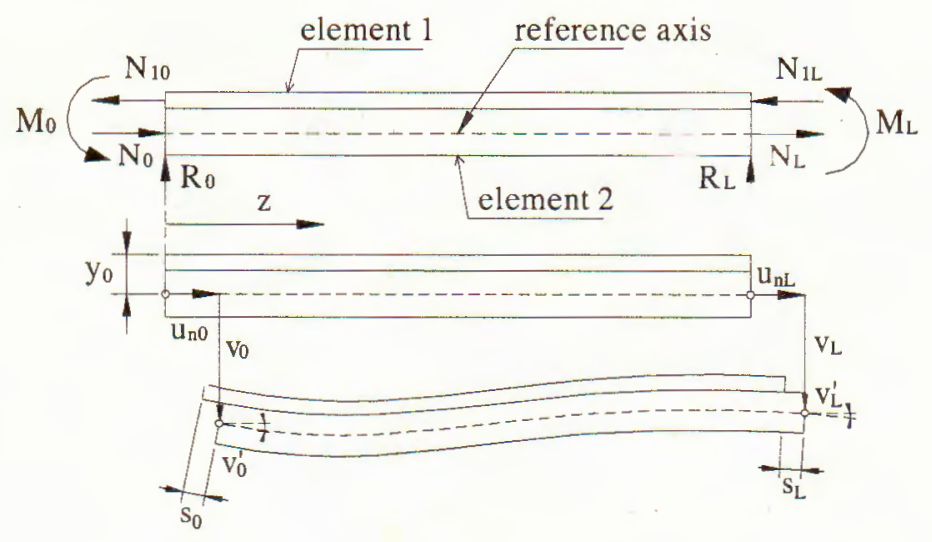

Fig. 5. Nodal Displacement, End Actions and Slip

in which:

$$
\begin{aligned}
\alpha= & -\frac{S E_{1}^{2} A E_{2}+S E_{2}^{2} A E_{1}-I E A E_{1} A E_{2}}{A E I E-S E^{2}}, \\
\alpha_{1}= & \frac{S E_{1} A E_{2}-S E_{2} A E_{1}}{A E I E-S E^{2}}, \\
\alpha_{2}= & \frac{A E_{1} I E-S E_{1} B E}{A E I E-S E^{2}} .
\end{aligned}
$$

From (17),

$$
s=C_{1} e^{\mu z}+C_{2} e^{-\mu z}+s_{0, p}
$$

where: $\mu^{2}=\frac{k}{\alpha} ; s_{0, p}$ : depends on the nature of the applied load conditions

\subsection{The stiffness matrix $k$; the vector of the equivalent nodal loads}

\subsubsection{Equilibrium}

Using the beam illustrated in Fig. 3, Fig. 5 defines 8DOF to encompass vertical displacement, rotation and material slip.

From [3], [6], obtain element equilibrium by direct evaluation.

$$
\left[\begin{array}{llllllll}
k_{11} & k_{12} & k_{13} & k_{14} & k_{15} & k_{16} & k_{17} & k_{18} \\
& k_{22} & k_{23} & k_{24} & k_{25} & k_{26} & k_{27} & k_{28} \\
& & k_{33} & k_{34} & k_{35} & k_{36} & k_{37} & k_{38} \\
& & & k_{44} & k_{45} & k_{46} & k_{47} & k_{48} \\
& & & & k_{55} & k_{56} & k_{57} & k_{58} \\
& & & & & k_{66} & k_{67} & k_{68} \\
& & & & & & k_{77} & k_{78} \\
S Y M & & & & & & & k_{88}
\end{array}\right]\{q\}=\{g\}+\left\{g_{e q}\right\}
$$

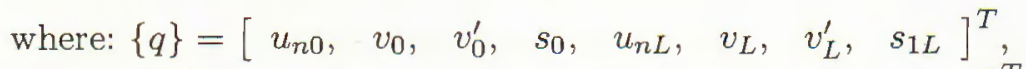

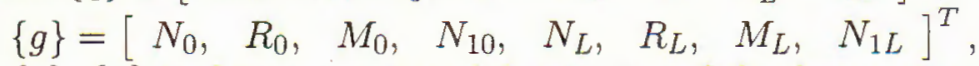

$\{q\},\{g\}$ is the vector of nodal actions and displacements, 
$\left\{g_{e q}\right\}$ is the vector of equivalent nodal.

\subsubsection{The stiffness matrix $K$}

The stiffness matrix $K$ is obtained by restraining all DOF save the one related to the column considered, to which a unit displacement is applied.

The moment and the axial force along the beam can be expressed as

$$
M=-M_{0}+R_{0} z ; \quad N=-N_{0}
$$

The slip can be expressed in the form

$$
s=C_{1} e^{\mu z}+C_{2} e^{-\mu z}-\frac{\alpha_{1}}{k} R_{0}
$$

The first column of the stiffness matrix $K$

The load state is given by

$$
\{q\}=\left[\begin{array}{llllllll}
1, & 0, & 0, & 0, & 0, & 0, & 0, & 0
\end{array}\right]_{(1)}^{T}
$$

From (19) and (22),

$$
\begin{aligned}
& {\left[\begin{array}{llllllll}
k_{11} & k_{12} & k_{13} & k_{14} & k_{15} & k_{16} & k_{17} & k_{18} \\
& k_{22} & k_{23} & k_{24} & k_{25} & k_{26} & k_{27} & k_{28} \\
& & k_{33} & k_{34} & k_{35} & k_{36} & k_{37} & k_{38} \\
& & k_{44} & k_{45} & k_{46} & k_{47} & k_{48} \\
& & & k_{55} & k_{56} & k_{57} & k_{58} \\
S Y M & & & k_{66} & k_{67} & k_{68} \\
0 \\
k_{11} \\
k_{21} \\
k_{31} \\
k_{41} \\
k_{51} \\
k_{61} \\
k_{71} \\
k_{81}
\end{array}\right\}=\left\{\begin{array}{l}
N_{0} \\
R_{0} \\
M_{0} \\
N_{10} \\
N_{10} \\
R_{L} \\
M_{L} \\
N_{1 L}
\end{array}\right\}}
\end{aligned}
$$

The stiffness coefficients of the first column are derived by Eq. (23). The constant of integrations: $C_{1} ; C_{2} ; D_{1} ; D_{2}$ and $D_{3}$ are determined by noting $s_{0}=0, s_{L}=0, \nu_{0}=0, \nu_{L}=$ $0, u_{n 0}=1$. The actions $N_{0}, R_{0}, M_{0}$ can be determined after noting $\nu^{\prime}=0, \nu_{L}^{\prime}=0, u_{n L}=0$.

From consideration of statics, obtain the nodal actions $N_{L}, R_{L}, M_{L}$ are:

$$
N_{10}=\left.N_{1}\right|_{Z=0} ; N_{1 L}=-\left.N_{1}\right|_{Z=L}
$$

2.3.3. Equivalent nodal loads due to uniform load $\boldsymbol{w}$

The moment and the axial force along the beam can be expressed as

$$
M=-M_{0}+R_{0} z-\frac{w z^{2}}{2} ; \quad N=-N_{0}
$$


The slip equilibrium can be expressed as

$$
s=C_{1} e^{\mu z}+C_{2} e^{-\mu z}-\frac{\alpha_{1}}{k} R_{0}+\frac{\alpha_{1} w}{k} z
$$

The enforcing the kinematic state is described as

$$
\{d\}=\left[\begin{array}{llllllll}
0, & 0, & 0, & 0, & 0, & 0, & 0, & 0
\end{array}\right]_{(q)}^{T}
$$

Similarly to 2.3 .2 , the vector of equivalent nodal loads is determined.

\section{APPLICATIONS}

\subsection{Built in composite beam subject to a uniform load $w$}
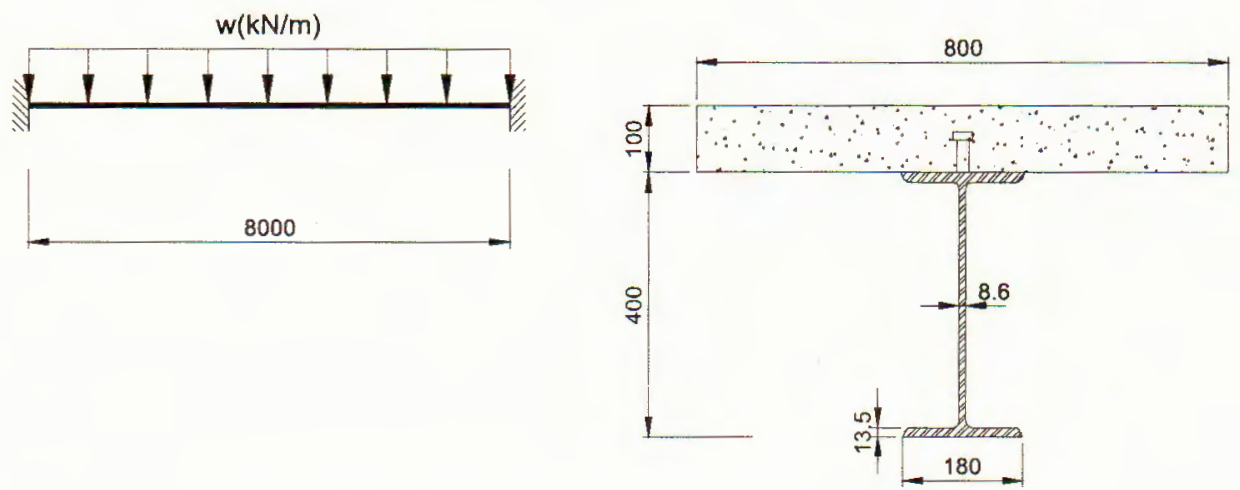

Fig. 6. Built-In beam and composite cross-section

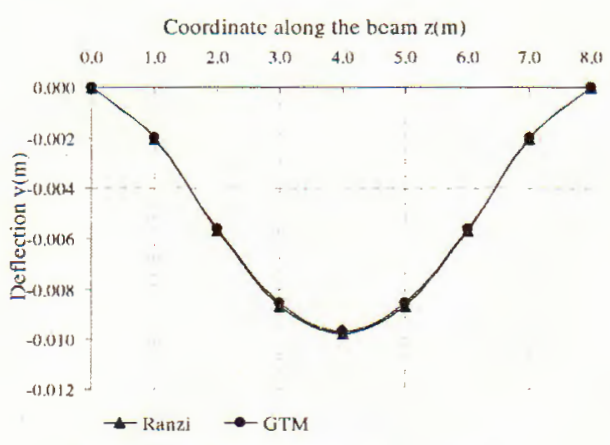

Fig. 7. Deflection $\mu \mathrm{L}=11.02$

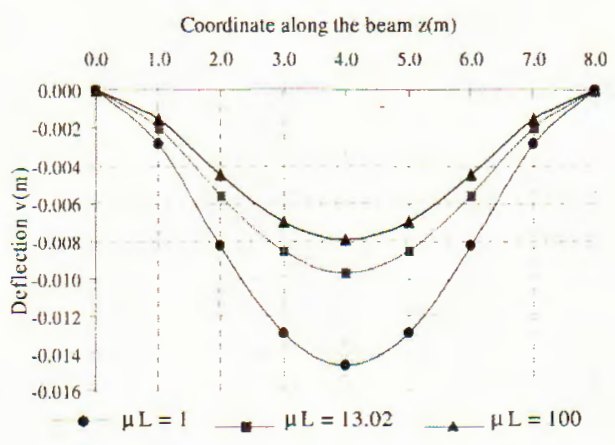

Fig. 8. Deflection versus $\mu \mathrm{L}$

For the beam shown in Fig. 6, let $E_{c}=2.1 \times 10^{7} \mathrm{KPa}, E_{s}=2.1 \times 10^{8} \mathrm{KPa}$ and the shear connection stiffness $k=8.33 \times 10^{5} \mathrm{KPa}$. Using only one element to complete the analysis using the proposed model (GTM) yields a calculated deflection in perfect agreement with results presented in [5]. Fig. 8 predicts beam deflections for various values of shear connection stiffness (in terms of the dimensionless parameter $\mu L$ ). 


\subsection{Double Span Beam}

Fig. 9 illustrates the 2 span continuous beam labeled CTB4 in Ansourian [7], in which $E_{c}=1.565 \times 10^{7} \mathrm{KPa}, E_{r}=1.565 \times 10^{7} \mathrm{KPa}, E_{s}=1.565 \times 10^{7} \mathrm{KPa}, A_{r}=160 \mathrm{~mm}^{2}$ and shear connection stiffness $k=0.982 \times 10^{6} \mathrm{KPa}$.

Using twelve stiffness elements to analysis the left span deflection. The results shown in Table 1 and in Fig. 10. It can be seen good result with linear behaviour of material. This highlight ability demonstrated the advantages of the general technique method.
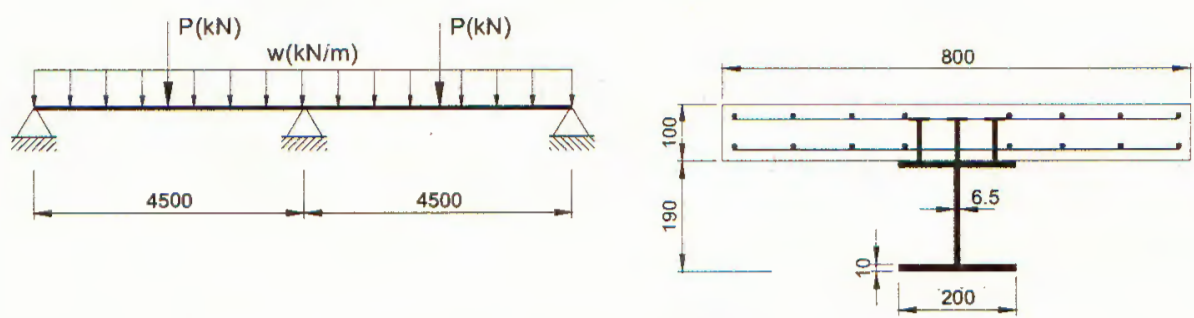

Fig. 9. 2 span beam and composite cross-section

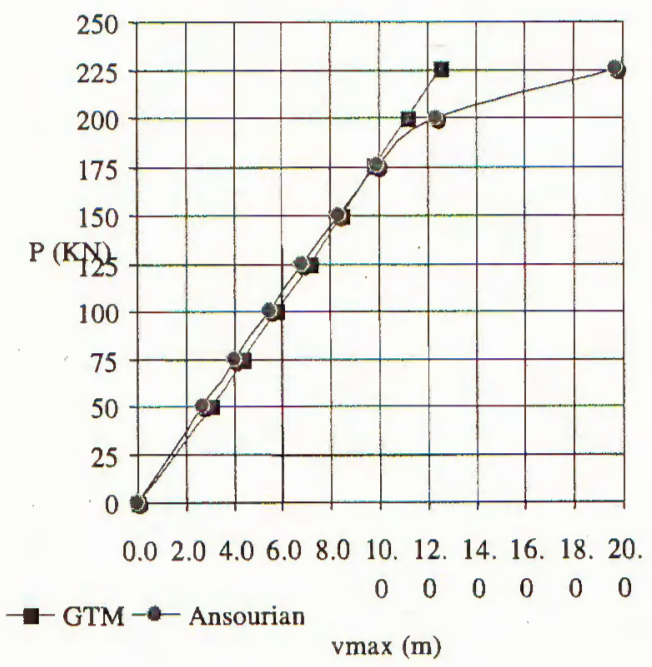

Fig. 10. Left Span Deflection) 
Table 1. Left Span middle deflection

\begin{tabular}{|c|c|c|c|}
\hline \multirow{2}{*}{ LoadP $(\mathrm{KN})$} & \multicolumn{2}{|c|}{ Deflection $v_{\max }(\mathrm{mm})$} & Comparision $(1) \&(2)(\%)$ \\
\cline { 2 - 4 } & GTM(1) & Ansourian $(2)$ & \\
\hline 0 & 0.000 & 0.000 & 0.000 \\
\hline 50 & 3.037 & 2.720 & 11.654 \\
\hline 75 & 4.399 & 4.017 & 9.510 \\
\hline 100 & 5.762 & 5.461 & 5.512 \\
\hline 125 & 7.125 & 6.801 & 4.764 \\
\hline 150 & 8.488 & 8.346 & 1.701 \\
\hline 175 & 9.815 & 9.941 & -1.267 \\
\hline 200 & 11.215 & 12.329 & -9.036 \\
\hline 225 & 12.577 & 19.741 & -36.290 \\
\hline
\end{tabular}

\section{CONCLUSIONS}

This paper describes a general modeling technique for the analysis of steel-concrete composite beams with elastic shear connection (partial interaction). The curvature, the rotation and the deflection formulation have obtained by using this model. Then derivation stiffness matrix $\mathrm{K}$ and application in the finite element method to analysis of the composite beams. (This is the $3^{\text {rd }}$ time this same sentence appears in this paper!!)

The results obtained have demonstrated the advantages and the confidence of the GMT method in comparision with the other results and experimental test. Model is simply, this method need to research to analysis composite beam for various loading.

\section{ACKNOWLEDGMENTS}

This work has been supported by a research project no T-KTXD 2007-31 of University of technology, VNU-HCMC.

\section{REFERENCES}

1. N. M. Newmark, C. P. Siess, I. M. Vies, Test and analysis of composite beams with incomplete interaction, Proc. Soc. Exp. Stress Anal. 9 (1) (1951) 75-92.

2. D. J. Oehlers, M. A. Bradford, Composite steel and concrete structural members: fundamental behaviour, 1995; Oxford: Pergamon Press.

3. Yasunori Arizumi and Sumio Hamada, Elastic-plastic analysis of composite beams with incomplete interaction by element method, Computer \&6 Structures 14 (5-6) (1981) 453-462.

4. C. Faella, E. Martinell, E. Nigro, Steel and concrete composite beams with flexble shear connection: "cxact" analytical exprossion of the stiffness matrix and application. Computer Struct 80 (2002) 1001-1009.

5. G. Ranzi, M. A. Bradford, B. Uy, A general method of analysis of composite beams with partial interaction, Steel and composite structures 3 (2) (2003) 169-184.

6. G. Ranzi, M. A. Bradford, Direct stiffness of a composite beam-column element with partial interaction, Comput Struct, 2007.

7. P. Ansourian, Experiments on continous composite beams, Proc Inst Eng 71 (1981) (Part2) 25-51. 
Received March 10, 2008

\section{PHÂN TÍCH DÀ̀M THÉP-BÊ TÔNG LIÊN HợP CÓ XÉT ẢNH HƯỞNG TƯONG TÁC BÁN PHÀ̀N Ở MẠTT TIẾP XƯC BẰNG PHƯONG PHÁP KỸ THUẬT TỔNG QUÁT}

Bài báo trình bày mô hình kỹ thuật tổng quát dựa trên mô hình kỹ thuật của Newmark để mô tả ứng xử của dầm thép-bê tông liên hợp với liên kết chịu cắt tuyến tính. Sử dụng mô hình này xây dựng các phương trình chuyển vị́, biến dạng của phần tử dưới tác dụng của tải trọng tĩnh và sử dụng các phương trình này xác định ma trận độ cứng $K$. Áp dụng kết quả vào phương pháp phần tử hữu hạn để khảo sát các bài toán cơ bản. Kết quả thu được so sánh với kết quả khác. 